\title{
Preface to the Special Topics on "Cutting-edge Technologies and Scientific Researches of Zinc and Zinc Alloy Coated Steel Sheets"
}

\author{
Ryosuke KAINUMA $^{1 / *}$ and Shu YAMAGUCHI ${ }^{21}$ \\ 1) Department of Materials Science, Graduate School of Engineering, Tohoku University, Sendai, 980-8579 Japan. \\ 2) Department of Materials Engineering, School of Engineering, The University of Tokyo, Tokyo, 113-8656 Japan.
}

Within the field of surface treatment technology for plating, especially for galvanized (GI) and galvannealed (GA)) steels, understanding factors to control the microstructure and various properties of the coating layer is important for improving the corrosion resistance and mechanical properties of the plating layer. However, basic research lags behind practical research, leading to a lack of connection between research and manufacturing applications. Recently, breakthrough technologies have been called for to meet demands for vehicle weight reduction, and for environmental friendliness. Furthermore, some advanced techniques, such as micromachining, high performance TEM and EPMA etc., have been developed. For these reasons, basic research aimed at breakthroughs in GI and GA steels has received much attention.

In this state of heightened interest, the 11th International Conference on Zinc and Zinc Alloy Coated Steel Sheet (Galvatech 2017) was successfully held at The University of Tokyo from November 12 to 16, 2017, with 138 oral and 31 poster presentations by 322 participants from 27 countries. Many interesting and important papers were presented, including in the inaugural session of a new series titled "Advanced Basic Research". In this special Topics, original and review papers on the recent technologies and forefront research for $\mathrm{Zn}$ and $\mathrm{Zn}$ alloy coated steels, such as (1) Innovative analysis on surface and interface structure, (2) Corrosion mechanism, (3) Thermodynamic assessment, and (4) Computer simulation and numerical analysis, were widely invited, including from presenters not present at Galvatech 2017. Twelve papers were selected for publication after critical review.

The Guest Editors want to thank all the contributors and reviewers for their efforts, the Organizing Committee Members of Galvatech 2017 for their cooperation, and the editorial board of the Iron and Steel Institute of Japan, for editing this special Topics.

* Corresponding author: E-mail: kainuma@material.tohoku.ac.jp

DOI: http://dx.doi.org/10.2355/isijinternational.58.1549 